УДК 37

DOI $10.21661 / \mathrm{r}-554940$

\title{
Т.В. Дубынина
}

\section{РАЗВИТИЕ ПОЗНАВАТЕЛЬНОГО ИНТЕРЕСА К МАТЕМАТИКЕ ВО ВНЕУРОЧНОЙ ДЕЯТЕЛЬНОСТИ}

Аннотация: в статье рассматривается проблема создания необходимых и достаточных условий формирования функииональной грамотности, в частности математической грамотности и математической культуры обучающиххся. Описаны результаты систематической практической деятельности по формированию и развитию познавательного интереса к математике, результаты педагогического наблюдения за стадиями развития этого качества во внеурочной деятельности. Описаны формы организации и подходы, используемые для эффективного взаимодействия обучающихся и педагогов.

Ключевые слова: проектная деятельность, познавательная активность, внеурочная деятельность, познавательный интерес, функциональная грамотHость.

«Познание начинается

с удивления тому, что обыденно»

Платон.

Одним из основных направлений реализации Концепции развития математического образования в Российской Федерации является «...обеспечение каждого обучающегося развивающей интеллектуальной деятельностью на доступном уровне, используя присущую математике красоту и увлекательность». Именно это направление подразумевает формирование познавательного интеpeca, как наиболее предпочитаемого мотива среди других мотивов деятельности. Познавательный интерес, создавая внутреннюю среду развития, существенно меняет силу деятельности, влияет на характер её протекание и результат. 
Интерес к математике (как и к любому другому предмету, согласно теории Г.И. Щукиной) проходит четыре стадии развития: любопытство, любознательность, познавательный интерес и теоретический (творческий) интерес. Формирование такого качества требует системного подхода и может успешно реализовываться на всех ступенях образования, при этом необходимо учитывать возрастные и индивидуальные особенности личности обучающихся [6].

Первая стадия, любопытство, выражает избирательное отношение к предмету, исходя из качеств, которые могли случайно привлечь внимание или вызвать некоторое удивление это может быть исторический факт, знакомство с необычным объектом, нестандартная ситуация, занимательная игра, необычная форма. Занятия математикой должны обязательно содержать ситуацию «удивления обыденному», поиску математической составляющей в привычном объекте. Это, на наш взгляд, своего рода реклама умственного труда, выбор направления деятельности. Длительное любопытство может переходить в любознательность, которая характеризуется, как черта характера, то есть личностное качествовнутренний мотиватор. Любознательность делает ум ищущим, пытливым, определяет вектор направленности деятельности - познавательный интерес, который в дальнейшем позволяет человеку активно воздействовать на мир, формирует мировоззрение, дальнейшие активные цели, то есть теоретический (творческий) интерес.

Конечно, не все дети выберут занятия математикой в качестве своей профессиональной деятельности, но даже если мы сможем добиться состояния любознательности, это будет способствовать развитию математического образования и повышению уровня образовательных результатов.

Одним из способов реализации этого является внеурочная деятельность. Она может осуществляться в разных формах. Например, математический кружок, в рамках которого проводятся систематические занятия с обучающимися, или работа в проектных группах по подготовке тематического мероприятия, или индивидуальные занятия. В любом случае, целью такой деятельности должно стать развитие любознательности, как необходимого условия познавательного 
интереса к математике, расширение кругозора, творческой смекалки, эрудиции, воспитанию культуры математического мышления.

В нашей образовательной организации внеурочная деятельность осуществляется во всех перечисленных формах. Кружки доступны всем обучающимся, не зависимо от результатов успеваемости по предмету. Ведущий учитель способствует созданию среды (образовательного пространства) в которой каждый ребёнок может реализовать свой потенциал. Обязательная математическая подготовка происходит непрерывно в течение всего учебного года. При этом согласно ФГОС, во внеурочных занятиях используются преимущественно активные методы обучения: игры, квесты, математические бои. В результате успешной деятельности кружка неизбежно формируются группы заинтересованных детей, с которыми можно выполнять коллективные проекты - проектные группы. Это может быть подготовка тематических газет, предметных спектаклей, викторин, в результате у этой группы детей формируется познавательный интерес к математике. Главной задачей при этом становится создание атмосферы творчества, плодотворной совместной работы. В проектных группах обычно выделяются дети, которые имеют более высокие по сравнению с большинством остальных интеллектуальные способности, доминирующую, активную познавательную потребность. Они способны испытывать радость от умственного труда, имеют характерную высокую скорость развития интеллектуальной и творческой сфер, глубину и не традиционность мышления. При работе с такими детьми педагог должен переориентироваться от формирования универсальных учебных действий на деятельность по проектированию и организации образовательных процедур, которые способствуют реализации теоретического интереса к математике. С такими детьми целесообразно заниматься индивидуально. В рамках индивидуальных занятий осуществляется подготовка проектов, самостоятельная исследовательская деятельность, подготовка к участию в конкурсах или олимпиадах, подготовка к участию в конференциях и форумах. Педагог должен адаптировать основную программу курса внеурочной деятельности для каждого обучающегося, с учётом индивидуальных особенностей и познавательных 
потребностей. В качестве диагностического инструмента можно использовать школьные олимпиады, конкурсы проектов, конкурсы исследовательских работ, интеллектуальные соревнования по каждому разделу программы (математический бой, математическая драка, математическая дуэль, викторины). Результаты внеурочной деятельности открывают проблемные зоны, определяют точки роста, проектируют новые направления деятельности. Например, учитывая данные социальных опросов в рамках учебных проектов, мы выяснили, что самым трудным разделом математики по-прежнему, остаётся геометрия. Именно поэтому, во внеурочной деятельности мы пытаемся добиться познавательного интереса к этой области. Участвуем в социальных проектах, создаём геометрические газеты (только треугольники или только окружности), знакомимся с необычными геометрическими фигурами, изучаем инструменты геометрии. В своей практической деятельности мы активно используем такое увлекательное направление как оригами, способствующее развитию геометрического мышления. В настоящее время обучение геометрии при помощи оригами практикуется в школах многих развитых стран. На занятиях по математике при помощи оригами можно отработать такие понятия как горизонтальные, вертикальные, наклонные линии; квадраты (сложи квадрат разными способами, покажи смежные стороны, диагональ); все виды треугольников. В процессе изготовления фигурок по схемам, развивается пространственное воображение, логика. Происходит формирование понятий (сторона угол, вершина угла, диагональ, центр фигуры). Складывается первоначальное представление о свойствах геометрических фигур (треугольник, прямоугольник, квадрат, ромб, произвольный четырёхугольник). Получаемые объекты настолько красивы и необычны, что любопытство у обучающихся возникает точно, любознательность проявляется в самостоятельной работе, а познавательный интерес в совместной проектной деятельности.

Знакомство с инструментами геометрии происходит при решении задач на построение, но для чистоты построений необходима линейка без делений, иначе дети не видят необходимости в том, чтобы так усложнять построение отрезка равного данному, или биссектрисы угла. В результате некоторые не умеют 
пользоваться циркулем. Построение узоров, без применения графических редакторов, только при помощи циркуля, как показывает практика, очень увлекательное занятие для обучающихся. В процессе такой работы можно чётко сформулировать понятия окружность и круг, дуга, центр, диаметр, радиус, хорда, центральный и вписанный угол.

Работа наших проектных групп была направлена на создание математических газет с заданными формами, постановку спектакля «Геометрическая сказка». В процессе работы выделились и индивидуальные траектории: творческий проект «Альтернативные способы доказательства теоремы Пифагора» позволил создать головоломку, иллюстрирующую доказательство теоремы Пифагора. Были начаты долгосрочные проекты «Необычные геометрические фигуры», «Геометрия - это просто», «Геометрия звёздного неба». Некоторые из них получили высокую оценку на международном конкурсе «Старт в науке». Достойным итогом стала защита индивидуального социального проекта «Геометрия - это просто», работа над которым началась в 5-м классе, тогда он назывался «Путешествие в страну Геометрию: орнамент и бордюр». Результаты проектной работы вполне могут послужить развитию познавательного интереса, ведь поставленная цель: «Способствовать повышению интереса к геометрии, посредством создания необычного наглядного материала, иллюстрирующего геометричность окружающего мира, который будет интересен ученикам, поднимет настроение, повысит мотивацию к изучению геометрии», - полностью достигнута.

Как пишет юный автор: «Не каждому дано увидеть красоту в строгих математических формулах и получать удовольствие от решения сложной задачи. Но надо помнить, что математика пришла к нам из окружающего мира, который мы пытаемся изучать. Значит, ответы на математические вопросы находятся вокруг нас». Думаю, что в этом человеке нам удалось развить познавательный интерес. Другой долгосрочный проект начинался в 5-м классе как исследовательская работа «Геометрические сказки: фракталы», первоначальной целью было показать, насколько процесс изучения математики может быть красивым и 
увлекательным. На протяжении пяти лет работа развивалась в процессе роста и развития ребёнка и наши «Геометрические сказки» постепенно трансформировались в аналитическое исследование с элементами творчества «Необычные геометрические фигуры». В 2020 г. эта работа была удостоена диплома II степени на региональном этапе конкурса «Шаг в будущее» и диплома III степени на международном конкурсе «Старт в науке».

При формировании познавательного интереса во внеурочной деятельности особое внимание следует уделять совершенствованию и развитию у детей экспериментальных навыков, умений применять знания в нестандартной ситуации, становлению функциональной грамотности. Развитию математической грамотности способствует организация деловых игр с использованием банка задач, условия задач можно адаптировать, учитывая региональные особенности. При проведении занятий используются такие приёмы мыслительной деятельности как анализ - синтез, дедуктивный метод, метод мозгового штурма.

Развитию познавательного интереса способствует постановка тематических спектаклей, в процессе подготовки, к которым отрабатываются важные определения и понятия, обучение происходит с применением игровой технологии. Такими спектаклями для нас стали урок-игра «Цифры и числа» (элементы теории чисел) и «Геометрическая сказка» (повторение курса геометрии 7 класс). Очень увлекательно прошёл урок-квест «Деньги любят счёт», игра-путешествие «Математическая полянка» $[1 ; 2 ; 5]$. При проведении занятий в игровой форме, присутствует не только соревновательный момент, но и формируется умение вести коллективную творческую деятельность. Совместное построение математических моделей процессов, объектов, явлений как в форме уравнений, таблиц, графиков, так и в виде пространственных представлений с помощью стереометрического прибора, мобильных моделей, конструкторов способствует развитию коммуникативных умений, выраженных в умении аргументированно доказывать, прислушиваться к мнению других, признавать свои ошибки, быть терпимым. 
Новым направлением внеурочной работы стала комбинаторика и теория графов, в рамках индивидуальной внеурочной работы мы попытались сформулировать и решить задачу о Кыштымских мостах (аналогично задаче Эйлера), рассмотрели граф транспортной сети региона. В рамках другого индивидуального занятия, учитывая интересы ребёнка, разбирали решение олимпиадной задачи о раскрасках с использованием методов комбинаторики, которое превратилось в графический эксперимент.

При организации внеурочной деятельности мы активно используем сайт «Малый мехмат - школе» на котором помещены методические разработки, созданные ведущими преподавателями Малого мехмата МГУ для проведения математических кружков в общеобразовательных школах. Каждая методическая разработка состоит из пособия для руководителя кружка, сопровождаемого готовым к печати набором заданий для обучающихся, и представляет одну из двух методических линий. Первая линия рассчитана на 4-х летний срок, вторая на 2,5 года планомерной работы. К задачам листков даны краткие рекомендации, предназначенные для учителя. При проведении занятий используются игровые технологии, технология опережающего обучения, проблемный метод.

Другим эффективным, на наш взгляд ресурсом является сайт «mäth us!», созданный Игорем Яковлевым, кандидатом физико-математических наук, выпускником МФТИ. На сайте представлены методические материалы для работы со школьниками с 5-го по 11 класс. Материалы этого сайта могут быть использованы для подготовки к математическим олимпиадам такого уровня как Всероссийская МО, «Ломоносов», «Покори Воробьёвы горы», «Высшая проба», а также к инженерной олимпиаде «Звезда». Дидактический материал разбит на разделы, соответствующие тематике олимпиадных задач и возрастной категории.

Сайт Николая Андреева «Математические этюды» существенно помогает нам в создании ситуации «удивления обыденному» и выбору тем исследований. При создании сайта, в качестве цели стоял ответ на вопрос: «Как увлечь детей наукой?». На сайте представлены этюды, выполненные с использованием современной компьютерной 3D графики увлекательно и интересно 
рассказывающие о математике и её приложениях. Изучение материалов сайта, по нашему мнению, способствует развитию любознательности и познавательного интереса к математике не только как к школьному предмету, но и как к науке и мотивирует обучающихся на исследовательскую деятельность.

Кроме цифровых и электронных ресурсов, мы используем печатные издания. Серия «Школьные математические кружки», издательства МЦНМО, Москва является источником ситуационных математических задач в различных сферах нашей жизни. Участие в международном математическом конкурсе «Кенгуру» пополняет библиотечку нашего кабинета математики новыми альманахами, выпусками журнала «Курсор», дидактическими играми.

При подведении итогов следует обратить внимание ещё на одну форму внеурочной деятельности - коррекционную работу. Очень часто обучающиеся, недостаточно усвоив отдельные темы, теряют опору и не могут достичь предметных результатов по психологическим причинам. Задача учителя не только дать знания, но и добиться устойчивого психоэмоционального состояния ребёнка, настроя на результат и адекватное принятие неудачи. Результат коррекционной работы - один из показателей эффективности работы учителя. Форм организации такой работы множество, главное выбрать их с учётом индивидуальности личности и возможности применения в каждом конкретном случае.

Завершая своё выступление, хочу пожелать коллегам продуктивной работы, вдохновения, творческой фантазии, интуиции на основе практического опыта при выборе форм и методов обучения одной из самых удивительных и важных наук - математике.

\section{Сиисок литературы}

1. Фарков А.В. Математические олимпиады: методика подготовки / А.В. Асмолов. - М.: ВАКО, 2015. - 176 с.

2. Анфимова Т.Б. Математика. Внеурочные занятия. 5-6 классы / Т.Б. Анфимова. - М.: ИЛЕКСА, 2015. - 128 с.

3. Лепёхин Ю.В. Математика. 7-8 классы: задания для подготовки к олимпиадам / Ю.В. Лепёхин. - Волгоград: Учитель, 2014. - 296 с. 
4. Математика. 5-9 классы. Развитие математического мышления: олимпиады, конкурсы / авт.-сост. И.В. Фотина. - Изд. 2-е, перераб. - Волгоград: Учитель. - 199 с.

5. Математика. 5-9 классы. Сценарии для предметной недели. Внеклассные мероприятия / авт.-сост. О.В. Панишева. - Волгоград: Учитель. - 169 с.

6. Спутник исследователя по педагогике / сост. А.М. Баскаков, Ю.Г. Соколова. - Челябинск: Издательство ООО «Полиграф-мастер», 2008. - 600 с.

Дубынина Татьяна Владимировна - учитель, МОУ «СОШ №13», Россия, Кыштым. 